\title{
Physical and Occupational Therapy From the Acute to Community Setting After Stroke: Predictors of Use, Continuity of Care, and Timeliness of Care
}

\author{
Janet K. Freburger, PT, PhD, ${ }^{a}$ Dongmei Li, MS, ${ }^{b}$ Anna M. Johnson, PhD, ${ }^{b}$ \\ Erin P. Fraher, $\mathrm{PhD}^{\mathrm{c}, \mathrm{d}}$
}

From the ${ }^{a}$ Department of Physical Therapy, University of Pittsburgh, Pittsburgh, PA; ${ }^{b}$ Department of Epidemiology, ${ }^{C}$ Cecil G. Sheps Center for Health Services Research, and ${ }^{d}$ Department of Family Medicine, University of North Carolina, Chapel Hill, NC.

\begin{abstract}
Objective: To identify predictors of therapist use (any use, continuity of care, timing of care) in the acute care hospital and community (home or outpatient) for patients discharged home after stroke.

Design: Retrospective cohort analysis of Medicare claims (2010-2013) linked to hospital-level and county-level data.

Setting: Acute care hospital and community.

Participants: Patients $(\mathrm{N}=23,413)$ who survived the first 30 days at home after being discharged from an acute care hospital after stroke. Interventions: Not applicable.

Main Outcome Measures: Physical and occupational therapist use in acute care and community settings; continuity of care across the inpatient and home or the inpatient and outpatient settings; and early therapist use in the home or outpatient setting. Multivariate logistic and multinomial logistic regression analyses were conducted to identify hospital-level, county-level, and sociodemographic characteristics associated with therapist use, continuity, and timing, controlling for clinical characteristics.

Results: Seventy-eight percent of patients received therapy in the acute care hospital, but only $40.8 \%$ received care in the first 30 days after discharge. Hospital nurse staffing was positively associated with inpatient and outpatient therapist use and continuity of care across settings. Primary care provider supply was associated with inpatient and outpatient therapist use, continuity of care, and early therapist care in the home and outpatient setting. Therapist supply was associated with continuity of care and early therapist use in the community. There was consistent evidence of sociodemographic disparities in therapist use.

Conclusions: Therapist use after stroke varies in the community and for specific sociodemographic subgroups and may be underused. Inpatient nurse staffing levels and primary care provider supply were the most consistent predictors of therapist use, continuity of care, and early therapist use. Archives of Physical Medicine and Rehabilitation 2018;99:1077-89
\end{abstract}

Presented to the Association of American Medical Colleges, May 5 2016, Chicago, IL; and the AcademyHealth, June 28 2016, Boston, MA

Supported through cooperative agreement U81HP26495, Health Workforce Research Centers, with the National Center for Health Workforce Analysis (NCHWA), Bureau of Health Workforce (BHW), Health Resources and Services Administration (HRSA), U.S. Department of Health and Human Services (HHS). The information, conclusions, and opinions expressed in this manuscript are those of the authors, and no endorsement by NCHWA, BHW, HRSA, or HHS is intended or should be inferred. The data used for this project was partially funded by the Pharmacoepidemiology Gillings Innovation Lab for the Population-Based Evaluation of Drug Benefits and Harms in Older US Adults (grant no. GIL 200811.0010), the Center for Pharmacoepidemiology, Department of Epidemiology, University of North Carolina Gillings School of Global Public Health; the CER Strategic Initiative of the University of North Carolina's Clinical Translational Science Award (no. UL1TR001111); the Cecil G. Sheps Center for Health Services Research, University of North Carolina; and the University of North Carolina School of Medicine.

Disclosures: none.
Approximately $80 \%$ to $90 \%$ of stroke survivors have residual movement impairment after stroke $\mathrm{k}^{1-3}$ and are vulnerable to inactivity, falls, and hospital readmission. ${ }^{4-8}$ Physical and occupational therapists play a key role in the rehabilitation of stroke survivors with movement impairments. ${ }^{1,2}$ Data suggest that early contact with a therapist and more intense therapy (eg, greater number of visits per time) may promote better recovery after stroke $\mathrm{e}^{9-12}$ and may decrease the risk of hospital readmission, falls, and other adverse health care events. ${ }^{13-15}$

While clinical practice guidelines recommend rehabilitation evaluation and treatment as soon as possible after hospital 
admission for stroke, ${ }^{11,16-18}$ short lengths of acute care stays shift most of the therapist care to postacute settings. Stroke survivors with more severe limitations, a lack of family support, or both, are more likely to be discharged to a postacute inpatient setting (eg, inpatient rehabilitation facility or skilled nursing facility), but most $(\sim 60 \%)$ are discharged directly home. ${ }^{19,20}$ Understanding the care pathway from the acute to community setting and the continuity of therapist care across settings has implications for determining whether patients are receiving appropriate and timely care; for delivering care via models that promote care coordination (eg, accountable care organizations, patient-centered medical homes) and team-based care; and for developing payment models that are bundled or episode based. Appropriate use of therapists in the acute and postacute community setting and continuity of care across settings maximize patient outcomes and may be effective in minimizing downstream health care costs. ${ }^{13,14}$

We aimed to describe the use of physical therapists and occupational therapists in the acute and postacute community settings (ie, home and/or outpatient setting) for patients who are discharged home after stroke, and to identify predictors of therapist use, continuity of therapist care across settings, and timing of therapist use in these settings. We were particularly interested in describing the extent to which contextual factors, at both the hospital and community level, explained variation in therapist use, as these factors may be mutable through intervention or policy changes. We also assessed sociodemographic variation in therapist use.

\section{Methods}

\section{Conceptual model}

Our conceptual model, derived from the literature on health care use and quality, illustrates that both clinical and nonclinical factors influence therapist use in the acute and postacute community settings (fig 1). We hypothesized that clinical factors (eg, stroke severity, comorbidities) or measures of "need" have the largest impact on therapist use, but sociodemographic factors (eg, race, insurance) also affect use. ${ }^{20}$ We also hypothesized that hospital characteristics such as patient volume and medical school affiliation were proxies for quality of care ${ }^{21-26}$ and would influence whether the patient received care from a therapist. Finally, we hypothesized that characteristics of the county (eg, provider supply) where the patient lived would be associated with therapist use.

\section{Data sources}

Our primary data source was a $20 \%$ random sample of Medicare claims (2010-2013) merged with data from the American Hospital Association database, the Centers for Medicare and Medicaid Services Provider of Services files, and the Area Health Resource file to obtain information on hospital characteristics where the patients were treated and health care supply and socioeconomic factors in the county where the stroke survivor resided.

\footnotetext{
List of abbreviations:

PCP primary care physician

PMR physical medicine and rehabilitation

RN registered nurse
}

\section{Study design and cohort}

We used a retrospective cohort design to identify Medicare beneficiaries admitted to short-term acute care hospitals for stroke between 2010 and 2013. We established a 6-month baseline period before the admission to assess comorbidities and health care use; the hospitalization period to assess comorbidities and clinical characteristics, as well as therapist use; and a 30-day period after discharge home to assess the use and timing of in-home and outpatient therapy (fig 2). We limited our sample to Medicare beneficiaries who (1) were aged $\geq 66$ years at admission (to ensure that cases were Medicare eligible during the 6-mo baseline period); (2) survived the hospital stay and were discharged home; (3) remained at home and survived the first 30 days after discharge; and (4) were continuously enrolled in Medicare Parts A and B. We excluded individuals hospitalized for stroke during the 6-month baseline period and individuals with a diagnosis of transient ischemic attack. We identified stroke based on primary and secondary International Classification of Diseases, Ninth Revision, Clinical Modification discharge diagnoses codes (supplemental table S1, available online only at http://www. archives-pmr.org/). ${ }^{27-31}$

\section{Explanatory and outcome variables}

Explanatory variables included clinical characteristics (characteristics of the hospitalization and comorbidities, baseline comorbidities, baseline health care use); sociodemographic characteristics (age, race, dual eligibility, income); hospital structural, organizational, human resource, and geographic characteristics (ownership, accreditation, medical school affiliation, Medicare and Medicaid discharges, bed size, registered nurse [RN] full-time equivalents per admission, metropolitan location); and countylevel characteristics where the patient lived (per capita primary care physician [PCP] supply, physical therapist supply, neurologist supply, physical medicine and rehabilitation [PMR] physician supply, metropolitan status).

We identified therapist use based on revenue center codes and Healthcare Common Procedure Coding System/Current Procedural Terminology codes for therapy-related procedures. ${ }^{32} \mathrm{We}$ created a dichotomous variable to indicate whether the patient received inpatient therapist care (yes, no), and 3 categorical variables to indicate whether the patient received postacute therapist care (in home, outpatient, no care), continuity of care (therapist care in the hospital and at home; therapist care in the hospital and outpatient setting; no continuity of care, defined as therapist care in hospital only), and early therapist care if the visit occurred below the median days to first visit (early care in home, early care in outpatient setting, later care). Explanatory and outcome variables are defined in detail in supplemental tables S2 through S4 (available online only at http://www.archives-pmr.org/).

\section{Analysis}

We first conducted descriptive analyses to identify therapist use in the inpatient, home, and outpatient settings. We then conducted multivariate logistic and multinomial logistic regression analyses to identify predictors of acute and postacute therapist use, continuity of care across the acute and community setting, and early postacute therapist use. All analyses were conducted in Stata version $14^{\mathrm{a}}$ using the robust SE option and clustering on hospital. 


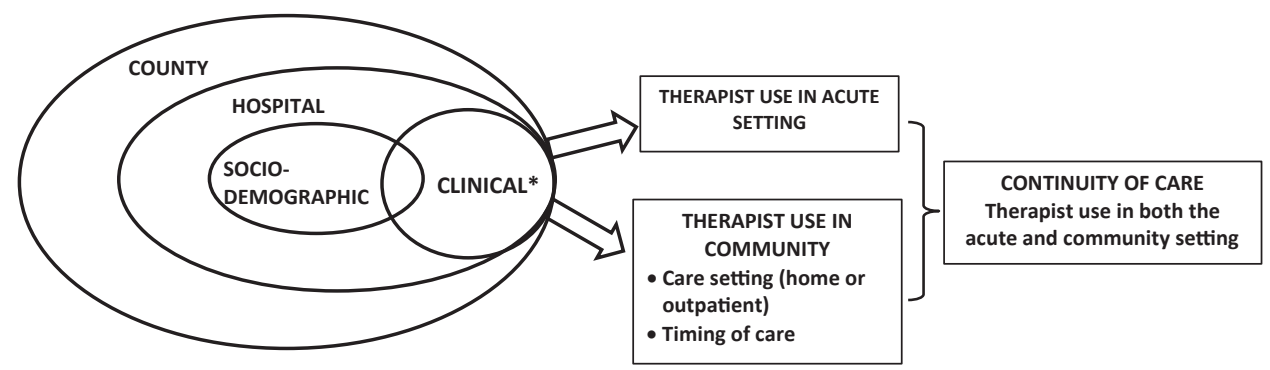

*the intersection of sociodemographic and clinical factors reflects the fact that it is sometimes difficult to disentangle sociodemographic factors (e.g., age) from need factors

Fig 1 Conceptual model.

\section{Sensitivity analyses}

We limited our analyses to the following subgroups to assess the extent to which our findings changed for patients who may have had a greater need for therapy: (1) patients with a primary discharge diagnosis of stroke; (2) patients with baseline or hospitalization comorbidities indicative of movement problems or frailty $^{33}$ (ie, aphasia, movement abnormalities, hemiparesis, falls, paralysis, renal failure, incontinence, neurologic problems, Parkinson disease, use of oxygen, use of a wheelchair, vertigo, use of an ambulance, use of assistive devices, use of therapy); and (3) patients who met both criteria.

The study protocol was reviewed and approved by the University of North Carolina's Institutional Review Board.

\section{Results}

Our sample consisted of 23,413 patients discharged home after stroke (supplemental fig S1, available online only at http://www. archives-pmr.org/). Seventy-eight percent of the sample received therapist care during their inpatient stay, but only $40.8 \%$ received care in the first 30 days after discharge. Thirty-seven percent of the sample received both inpatient and postacute care, and $18.0 \%$ received no acute or postacute therapy. Care was more likely in the home than in the outpatient setting during these first 30 days, with only about $10 \%$ of the sample receiving outpatient therapy.

Table 1 presents select sample characteristics stratified by therapist use. Patients who saw a therapist in the inpatient setting were slightly older, more likely to be women and black, had longer lengths of stay, and generally presented with more comorbidities indicative of functional limitations. Differences by demographic and clinical characteristics were more apparent when comparing postacute therapist use, and varied depending on

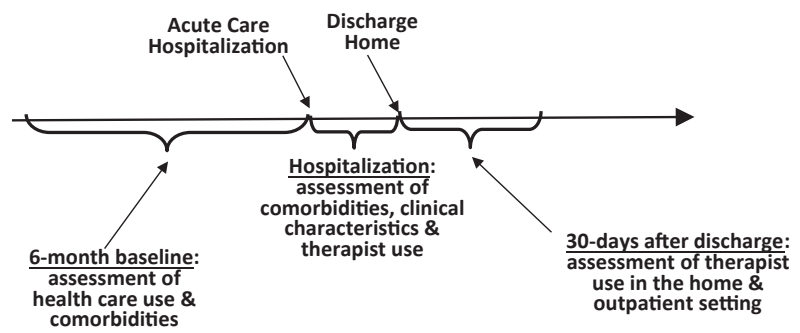

Fig 2 Study design. the characteristic and the comparison (eg, home vs outpatient vs no therapist). While patients who received no postacute care generally had lower rates of comorbidities and physical impairments relative to those who received postacute care, in many instances these rates were only slightly lower.

For patients who received home health therapy, the mean \pm SD and median number of days to the first visit was $5.2 \pm 4.6$ and 4 days, respectively, and the mean number of visits was $6.8 \pm 3.8$ (see table 1). For patients who received outpatient therapy, the mean $\pm \mathrm{SD}$ and median number of days to the first visit was $9.4 \pm 7.0$ and 7 days, respectively, with a mean $\pm \mathrm{SD}$ of $5.1 \pm 3.4$ visits.

\section{Predictors of therapist use in inpatient and postacute settings}

Patients treated at hospitals with higher RN staffing levels were more likely to be seen by an inpatient therapist, with a doseresponse relationship present (ie, odds ratios increasing as staffing ratios increased from 1.07 to 1.28 ) (table 2). Other hospital characteristics marginally associated with inpatient therapist use were being treated at a nongovernment, not-for-profit hospital (relative to a for-profit hospital) and being treated at a hospital located in a metropolitan area. Patients living in counties with a greater PCP supply were also more likely to receive inpatient therapist care, with a dose-response relationship present. Patients who were Hispanic or of a lower socioeconomic status were less likely to receive inpatient therapist care.

Patients seen at Joint Commission-accredited hospitals were more likely to receive therapy in the home, and there was some indication of an inverse relationship between bed size and use of therapy in the home. No county-level variables were associated with therapist use in the home. Patients who were black, dual eligible, and lived in counties with lower median household incomes were more likely to be seen by a therapist in the home.

Patients seen in hospitals with a higher proportion of Medicaid discharges were less likely to receive outpatient therapy, while those seen at hospitals with higher RN staffing levels were more likely. We also observed a dose-response relationship with the RN staffing variables. Patients living in counties with a higher PCP supply and physical therapist supply were also more likely to receive outpatient therapy, with dose-response relationships present. Patients who were black or dual eligible were less likely to see an outpatient therapist. 
Table 1 Sample characteristics by therapist use $(\mathrm{N}=23,413)$

\begin{tabular}{|c|c|c|c|c|c|}
\hline \multirow[b]{2}{*}{ Variables } & \multicolumn{2}{|c|}{ Inpatient Therapist Use } & \multicolumn{3}{|c|}{ Postacute Therapist Use } \\
\hline & Yes $(78.4 \%)$ & No $(21.6 \%)$ & In Home $(30.8 \%)$ & Outpatient* $(10.0 \%)$ & None $(59.2 \%)$ \\
\hline \multicolumn{6}{|l|}{ Demographic variables } \\
\hline Male & 42.4 & 43.9 & 34.0 & 50.0 & 46.0 \\
\hline Age $(y)$ & $77.8 \pm 7.6$ & $76.7 \pm 7.3$ & $79.8 \pm 7.7$ & $75.8 \pm 6.7$ & $76.7 \pm 7.3$ \\
\hline \multicolumn{6}{|l|}{ Race } \\
\hline White & 80.9 & 82.0 & 76.4 & 87.8 & 82.5 \\
\hline Black & 11.6 & 10.3 & 15.0 & 7.0 & 10.2 \\
\hline Hispanic & 2.7 & 3.6 & 3.8 & 1.6 & 2.7 \\
\hline Other & 4.7 & 4.1 & 4.8 & 3.6 & 4.6 \\
\hline Dual eligibility & 26.8 & 26.6 & 33.6 & 14.1 & 25.3 \\
\hline \multicolumn{6}{|l|}{ Hospitalization variables } \\
\hline \multicolumn{6}{|l|}{ Stroke } \\
\hline Hemorrhagic & 11.7 & 12.7 & 12.4 & 10.5 & 12.0 \\
\hline Ischemic & 88.3 & 87.3 & 87.6 & 89.5 & 88.0 \\
\hline ICU use & 38.4 & 31.8 & 37.8 & 36.7 & 36.6 \\
\hline CCU use & 14.8 & 14.2 & 15.6 & 13.2 & 14.5 \\
\hline Length of stay (d) & $3.9 \pm 3.5$ & $2.9 \pm 2.6$ & $4.6 \pm 4.1$ & $3.3 \pm 2.9$ & $3.4 \pm 2.9$ \\
\hline \multicolumn{6}{|c|}{ Stroke-related comorbidities during hospitalization } \\
\hline Aphasia & 11.8 & 7.9 & 11.4 & 10.3 & 10.8 \\
\hline Dysphagia & 4.1 & 2.0 & 5.8 & 3.9 & 2.5 \\
\hline Movement abnormalities & 7.8 & 3.7 & 8.0 & 10.8 & 5.8 \\
\hline Hemiparesis/plegia & 17.6 & 9.0 & 18.2 & 21.9 & 13.4 \\
\hline Fall & 0.8 & 0.6 & 1.1 & 0.6 & 0.5 \\
\hline \multicolumn{6}{|c|}{ Elixhauser comorbidities (baseline $\&$ hospitalization) } \\
\hline \multicolumn{6}{|c|}{ Comorbidity count } \\
\hline $0-1$ & 10.3 & 10.3 & 7.2 & 12.2 & 11.9 \\
\hline $2-4$ & 36.2 & 38.6 & 34.2 & 41.2 & 38.9 \\
\hline $5-7$ & 27.4 & 25.7 & 30.8 & 26.6 & 26.6 \\
\hline $8-10$ & 14.4 & 14.7 & 19.6 & 12.2 & 13.2 \\
\hline$>10$ & 11.7 & 10.7 & 18.3 & 7.8 & 9.5 \\
\hline Paralysis & 12.9 & 8.0 & 18.3 & 15.9 & 8.6 \\
\hline Other neurologic & 41.0 & 37.8 & 53.3 & 34.3 & 37.2 \\
\hline Obesity & 5.0 & 4.9 & 6.4 & 4.4 & 4.7 \\
\hline Depression & 11.3 & 10.7 & 16.6 & 9.7 & 9.4 \\
\hline \multicolumn{6}{|c|}{ Baseline comorbidities and health care use } \\
\hline Use of wheelchair & 1.8 & 1.4 & 3.2 & 0.8 & 1.3 \\
\hline Parkinson disease & 0.8 & 0.7 & 1.3 & 0.7 & 0.6 \\
\hline Weakness & 0.4 & 0.4 & 0.6 & 0.2 & 0.3 \\
\hline Vertigo & 6.3 & 7.4 & 6.8 & 6.8 & 6.7 \\
\hline History of a fall & 5.0 & 4.0 & 8.0 & 5.3 & 3.3 \\
\hline Use of oxygen & 4.6 & 4.0 & 6.6 & 2.3 & 4.0 \\
\hline Use of hospital bed & 1.0 & 1.2 & 2.1 & 0.3 & 0.8 \\
\hline Use of assistive devices & 1.8 & 1.6 & 2.8 & 1.2 & 1.4 \\
\hline$\geq 2$ Hospitalizations & 6.9 & 6.4 & 11.1 & 5.5 & 5.4 \\
\hline$\geq 1$ SNF admissions & 2.7 & 1.9 & 4.8 & 1.7 & 1.7 \\
\hline Use of inpatient PT or $0 \mathrm{~T}$ & 10.2 & 7.9 & 16.1 & 9.2 & 7.3 \\
\hline Use of PT or OT in home & 10.1 & 8.1 & 21.4 & 3.8 & 5.5 \\
\hline Use of outpatient PT or OT & 9.8 & 9.3 & 10.8 & 20.3 & 7.8 \\
\hline \multicolumn{6}{|l|}{ Therapist visits } \\
\hline Received inpatient PT & 96.9 & 0 & 99.6 & 87.2 & 66.5 \\
\hline Received inpatient OT & 67.5 & 0 & 68.9 & 68.7 & 45.3 \\
\hline No. of days to first visit & NA & NA & $5.2 \pm 4.6$ & $9.4 \pm 7.0$ & NA \\
\hline Median days to first visit & NA & NA & 4 & 7 & NA \\
\hline No. of visits & NA & NA & $6.8 \pm 3.8$ & $5.1 \pm 3.4$ & NA \\
\hline
\end{tabular}

NOTE. Values are \%, mean $\pm S D$, or as otherwise indicated.

Abbreviations: CCU, coronary care unit; ICU, intensive care unit; NA, not applicable; OT, occupational therapist; PT, physical therapist; SNF, skilled nursing facility.

* Restricted to patients who saw an outpatient therapist only. 


\section{Predictors of continuity of therapist use across settings}

Patients seen at Joint Commission-accredited hospitals were more likely to receive continuity of therapist care from the inpatient to home setting, while patients seen at larger hospitals were less likely (table 3). Patients who were black or dual eligible were more likely to have continuity of therapist care across the inpatient and home setting, while patients who lived in counties with higher median household incomes were less likely.

Patients treated at hospitals with a greater proportion of Medicaid discharges were less likely to receive continuity of therapist care across the inpatient and outpatient setting, while patients treated in hospitals with higher RN staffing levels were more likely. Patients living in counties with a greater supply of physical therapists were more likely to receive continuity of therapist care across the inpatient and outpatient setting. The association between increased PCP supply and continuity of care in the inpatient and outpatient setting approached significance. Patients who were black or dual eligible were less likely to have continuity of care across the inpatient and outpatient setting.

\section{Predictors of early postacute therapist care}

Patients treated at government hospitals and hospitals with a higher proportion of Medicaid discharges were more likely to receive early therapist care in the home, while those treated at hospitals with a medical school affiliation and larger hospitals were less likely to receive early care in the home (table 4). PCP supply and physical therapist supply were positively associated with early therapist use in the home, while PMR physician supply was inversely associated with early outpatient therapist use. Patients who were black or Hispanic were also less likely to receive early home therapy relative to patients who were white.

Patients treated at not-for-profit hospitals were more likely to receive early outpatient therapist care (see table 4). RN staffing levels were also positively associated with early outpatient therapist use, although these effects were marginal in regard to statistical significance. PCP supply and physical therapist supply were positively associated with early therapist care in the outpatient setting, while PMR physician supply was inversely related to early therapist care in this setting. Sociodemographic disparities in the use of early outpatient therapist care were also present. Patients who were black (relative to white) or dual eligible were less likely to receive early outpatient therapist care.

\section{Sensitivity analyses}

The point estimates for the associations observed in our subgroup analyses were generally similar to the estimates for the overall samples, but less precise (ie, wider confidence intervals) because of smaller samples sizes.

\section{Discussion}

Our results suggest there may be underutilization of therapists in the care of patients after stroke based on 2 factors: (1) current evidence or guidelines, or both, suggest that rehabilitation begin as soon as possible and be as intensive as possible after stroke $^{2,8,11,16-18}$; and (2) prevalence estimates suggest that $80 \%$ to $90 \%$ of individuals who sustain a stroke have some degree of motor impairment. ${ }^{1-3}$ While $78 \%$ of the sample received care in the inpatient setting, only $41 \%$ received care in the first 30 days after discharge home, a time when the patient is particularly vulnerable to inactivity, falls, and readmissions. ${ }^{4-8}$ Continuity of care across settings was also low. Of those who saw an inpatient therapist, less than half had contact with a therapist in the first 30 days after discharge. Receipt of therapist care after discharge is particularly important since stays in the acute setting are often too short to allow for substantive and complete rehabilitation.

Two consistent findings from our analyses were the positive relationships between RN staffing and therapist use, and PCP supply and therapist use. Patients treated in hospitals with higher RN staffing and living in counties with greater PCP supply were more likely to receive therapist care in the inpatient and outpatient settings and to have continuity of care across the inpatient and outpatient setting. PCP supply was also associated with the receipt of early therapist care in the home and outpatient setting, while $\mathrm{RN}$ staffing was associated with early therapist care in the outpatient setting only. A large body of literature has identified a positive relationship between RN staffing levels, patient outcomes, and quality of care. ${ }^{23,24,34}$ Our findings support the literature suggesting that hospitals with higher levels of nurse staffing may do a better job in getting patients timely rehabilitation care in the inpatient setting and planning their follow-up care postdischarge. Our findings regarding PCP supply also make theoretical sense because these are the providers patients are most likely to see after being discharged home after stroke. Timely contact with a PCP after hospital discharge can facilitate timely and appropriate access to other care, including therapist care, which requires a physician referral for Medicare patients. While therapist supply was associated with therapist use in some of our models, PCP supply was a more consistent predictor of therapist use across models. These findings suggest that policies to improve the distribution of PCPs may be as important as those to improve therapist distribution.

Contrary to what we expected, physician specialist supply (ie, neurologists and PMR physicians) was not positively associated with therapist use in most models. PMR physician supply, in particular, was inversely related to early therapist use in both the home and outpatient setting. While the reasons behind this are not clear, one explanation may be that PCPs refer to PMR physicians when available, but directly to physical therapists or occupational therapists when the PMR physician supply is low. An alternative explanation is that therapy is overprescribed in areas where PMR physician supply is low.

We found consistent evidence of racial and socioeconomic disparities in therapist use after stroke, particularly in regard to outpatient and early therapist use. Patients who were black or dual eligible were less likely to receive outpatient therapy after discharge home, and less likely to receive early outpatient therapy. Patients treated at hospitals with a higher proportion of Medicaid discharges were also less likely to receive outpatient therapy or to have continuity of care from the inpatient to outpatient setting. While patients who were black were more likely to receive therapist care in the home, they were less likely to receive this care early. Patients who were Hispanic were also less likely to receive early therapist care in the home and to receive inpatient therapist care.

Our findings on racial and socioeconomic disparities identify potential areas to target for improving access, particularly since patients who are black or of a lower socioeconomic status have a greater burden of disease in stroke, greater mortality, and greater 
Table 2 Hospital, county, and sociodemographic factors associated with therapist use in the inpatient setting and in the home or outpatient setting ( $\mathrm{N}=23,413$ )

\begin{tabular}{|c|c|c|c|c|c|c|}
\hline \multirow[b]{3}{*}{ Factors } & \multirow{2}{*}{\multicolumn{2}{|c|}{$\begin{array}{l}\text { Multivariate Logistic Regression: } \\
\text { Therapist Use in Inpatient Setting* }\end{array}$}} & \multicolumn{4}{|c|}{ Multivariate, Multinomial Logistic Regression Analysis ${ }^{\dagger}$} \\
\hline & & & \multicolumn{2}{|c|}{ Therapist Use in Home } & \multicolumn{2}{|c|}{ Therapist Use in Outpatient } \\
\hline & Odds Ratio $(95 \% \mathrm{CI})$ & $P$ & Odds Ratio $(95 \% \mathrm{CI})$ & $P$ & Odds Ratio (95\% CI) & $P$ \\
\hline \multicolumn{7}{|l|}{ Hospital-level characteristics } \\
\hline \multicolumn{7}{|l|}{ Ownership } \\
\hline Government & $0.87(0.73-1.03)$ & .10 & $1.04(0.90-1.20)$ & .63 & $1.03(0.83-1.27)$ & .77 \\
\hline Other not-for-profit & $1.13(0.99-1.28)$ & .06 & $0.93(0.83-1.03)$ & .18 & $1.10(0.94-1.30)$ & .24 \\
\hline Joint Commission-accredited hospital & $1.07(0.93-1.23)$ & .34 & $1.32(1.15-1.51)$ & $<.001$ & $0.98(0.84-1.15)$ & .82 \\
\hline Medical school affiliation & $1.03(0.93-1.13)$ & .60 & $0.97(0.89-1.06)$ & .49 & $1.04(0.93-1.17)$ & .48 \\
\hline \multicolumn{7}{|l|}{ No. of beds ${ }^{\S}$} \\
\hline 100 to $<200$ & $1.05(0.86-1.28)$ & .63 & $0.84(0.70-1.01)$ & .06 & $0.97(0.75-1.25)$ & .81 \\
\hline 200 to $<300$ & $1.07(0.84-1.35)$ & .60 & $0.78(0.63-0.96)$ & .02 & $0.95(0.71-1.27)$ & .72 \\
\hline 300 to $<400$ & $1.08(0.83-1.40)$ & .58 & $0.80(0.64-1.01)$ & .06 & $1.03(0.75-1.41)$ & .87 \\
\hline 400 to $<500$ & $1.12(0.84-1.50)$ & .43 & $0.73(0.57-0.93)$ & .01 & $0.91(0.65-1.28)$ & .59 \\
\hline$\geq 500$ & $1.02(0.76-1.36)$ & .91 & $0.80(0.63-1.02)$ & .08 & $0.86(0.61-1.22)$ & .40 \\
\hline \multicolumn{7}{|l|}{ Medicare discharges/admissions $\|$} \\
\hline 2nd quartile & $1.04(0.84-1.28)$ & .74 & $1.06(0.88-1.29)$ & .54 & $0.82(0.63-1.07)$ & .15 \\
\hline 3rd quartile & $1.13(0.88-1.45)$ & .34 & $0.97(0.78-1.21)$ & .80 & $0.77(0.57-1.04)$ & .09 \\
\hline 4th quartile & $1.18(0.89-1.57)$ & .25 & $1.04(0.82-1.32)$ & .76 & $0.83(0.60-1.17)$ & .29 \\
\hline \multicolumn{7}{|l|}{ Medicaid discharges/admissions $\|$} \\
\hline 2nd quartile & $1.01(0.90-1.13)$ & .87 & $0.96(0.88-1.06)$ & .43 & $0.94(0.82-1.08)$ & .39 \\
\hline 3rd quartile & $1.01(0.90-1.13)$ & .86 & $1.04(0.94-1.15)$ & .43 & $0.94(0.82-1.08)$ & .37 \\
\hline 4th quartile & $0.91(0.80-1.03)$ & .14 & $0.96(0.87-1.07)$ & .51 & $0.84(0.72-0.97)$ & .02 \\
\hline \multicolumn{7}{|l|}{ RN FTEs/admissions $\|$} \\
\hline 2nd quartile & $1.07(0.96-1.20)$ & .23 & $0.99(0.89-1.10)$ & .84 & $1.12(0.97-1.30)$ & .13 \\
\hline 3rd quartile & $1.24(1.10-1.40)$ & .001 & $0.98(0.88-1.09)$ & .69 & $1.22(1.04-1.43)$ & .01 \\
\hline 4th quartile & $1.28(1.13-1.46)$ & $<.001$ & $0.98(0.88-1.10)$ & .79 & $1.35(1.15-1.57)$ & $<.001$ \\
\hline Metropolitan location & $1.16(1.00-1.36)$ & .05 & $1.00(0.87-1.14)$ & .96 & $0.87(0.72-1.04)$ & .13 \\
\hline \multicolumn{7}{|l|}{ County-level variables } \\
\hline \multicolumn{7}{|l|}{ PCPs/population } \\
\hline 2nd tertile & $1.17(1.04-1.31)$ & .009 & $1.04(0.94-1.16)$ & .41 & $1.10(0.95-1.28)$ & .21 \\
\hline 3rd tertile & $1.29(1.13-1.46)$ & $<.001$ & $0.97(0.87-1.09)$ & .63 & $1.18(1.00-1.40)$ & .04 \\
\hline \multicolumn{7}{|l|}{ Neurologists/population } \\
\hline 2nd tertile & $0.95(0.83-1.09)$ & .45 & $1.02(0.90-1.16)$ & .76 & $0.98(0.82-1.17)$ & .84 \\
\hline 3rd tertile & $0.86(0.74-1.00)$ & .05 & $1.08(0.94-1.24)$ & .29 & $0.95(0.79-1.16)$ & .64 \\
\hline \multicolumn{7}{|l|}{ PMR physicians/population } \\
\hline 2nd tertile & $0.96(0.84-1.10)$ & .57 & $1.05(0.93-1.19)$ & .45 & $0.88(0.74-1.04)$ & .13 \\
\hline 3rd tertile & $0.95(0.82-1.10)$ & .50 & $0.99(0.87-1.14)$ & .93 & $0.92(0.77-1.11)$ & .41 \\
\hline
\end{tabular}

(continued on next page) 


\begin{tabular}{|c|c|c|c|c|c|c|}
\hline \multirow[b]{3}{*}{ Factors } & \multirow{2}{*}{\multicolumn{2}{|c|}{$\begin{array}{l}\text { Multivariate Logistic Regression: } \\
\text { Therapist Use in Inpatient Setting* }\end{array}$}} & \multicolumn{4}{|c|}{ Multivariate, Multinomial Logistic Regression Analysis ${ }^{\dagger}$} \\
\hline & & & \multicolumn{2}{|c|}{ Therapist Use in Home } & \multicolumn{2}{|c|}{ Therapist Use in Outpatient } \\
\hline & Odds Ratio $(95 \% \mathrm{CI})$ & $P$ & Odds Ratio (95\% CI) & $P$ & Odds Ratio (95\% CI) & $P$ \\
\hline \multicolumn{7}{|c|}{ Physical therapists/population } \\
\hline 2nd tertile & $1.01(0.88-1.15)$ & .94 & $1.00(0.88-1.13)$ & .96 & $1.14(0.94-1.37)$ & .18 \\
\hline 3rd tertile & $0.99(0.85-1.16)$ & .94 & $1.04(0.90-1.19)$ & .61 & $1.25(1.02-1.54)$ & .03 \\
\hline Metropolitan county & $1.03(0.90-1.18)$ & .66 & $1.04(0.94-1.16)$ & .41 & $0.96(0.80-1.14)$ & .63 \\
\hline \multicolumn{7}{|c|}{ Patient-level sociodemographic characteristics } \\
\hline \multicolumn{7}{|c|}{ Race $^{\#}$} \\
\hline Black & $1.06(0.93-1.22)$ & .38 & $1.27(1.14-1.41)$ & $<.001$ & $0.83(0.68-1.00)$ & .04 \\
\hline Hispanic & $0.71(0.57-0.89)$ & .003 & $0.97(0.79-1.19)$ & .76 & $0.93(0.64-1.35)$ & .69 \\
\hline Other & $1.09(0.90-1.31)$ & .37 & $0.97(0.83-1.15)$ & .74 & $0.91(0.69-1.21)$ & .53 \\
\hline Dual eligible & $0.96(0.87-1.05)$ & .34 & $1.15(1.06-1.25)$ & .001 & $0.54(0.47-0.62)$ & $<.001$ \\
\hline \multicolumn{7}{|c|}{ Median household income $e^{\|, * *}$} \\
\hline 2nd quartile & $1.17(1.01-1.35)$ & .04 & $0.89(0.79-1.02)$ & .09 & $1.03(0.84-1.26)$ & .80 \\
\hline 3rd quartile & $1.10(0.94-1.29)$ & .23 & $0.83(0.73-0.95)$ & .007 & $1.07(0.87-1.33)$ & .50 \\
\hline 4th quartile & $1.35(1.15-1.59)$ & $<.001$ & $0.93(0.82-1.06)$ & .30 & $1.13(0.91-1.40)$ & .26 \\
\hline
\end{tabular}

Abbreviations: CI, confidence interval; FTE, full-time equivalent.

* Reference no inpatient therapist use, controlling for sex, age, baseline comorbidities and health care use, hospitalization characteristics, and comorbidities.

Reference no therapist use in home or outpatient setting controlling for sex, age, baseline comorbidities and health care use, hospitalization characteristics, and comorbidities.

Reference for profit.

Reference $<100$ beds.

$\|$ Reference 1st quartile.

" Reference 1st tertile.

\# Reference white.

** County-level measure. 
Table 3 Hospital, county, and patient sociodemographic characteristics associated with continuity of therapy care $\left(N=18,357^{*}\right)$

\begin{tabular}{|c|c|c|c|c|}
\hline \multirow[b]{3}{*}{ Characteristics } & \multicolumn{4}{|c|}{ Multivariate, Multinomial Logistic Regression Analysis $^{\dagger}$} \\
\hline & \multicolumn{2}{|c|}{ Therapist Use in Hospital and Home } & \multicolumn{2}{|c|}{ Therapist Use in Hospital and Outpatient Setting } \\
\hline & Odds Ratio (95\% CI) & $P$ & Odds Ratio $(95 \% \mathrm{CI})$ & $P$ \\
\hline \multicolumn{5}{|l|}{ Hospital-level characteristics } \\
\hline \multicolumn{5}{|l|}{ Ownership } \\
\hline Government & $1.12(0.94-1.32)$ & .20 & $1.05(0.83-1.33)$ & .68 \\
\hline Other not-for-profit & $0.93(0.82-1.05)$ & .22 & $1.12(0.93-1.34)$ & .23 \\
\hline Joint Commission-accredited hospital & $1.30(1.13-1.50)$ & $<.001$ & $1.05(0.87-1.27)$ & .63 \\
\hline Medical school affiliation & $0.95(0.86-1.04)$ & .29 & $1.05(0.93-1.19)$ & .44 \\
\hline \multicolumn{5}{|l|}{ No. of beds $s^{\S}$} \\
\hline 100 to $<200$ & $0.81(0.66-0.99)$ & .04 & $0.97(0.73-1.27)$ & .80 \\
\hline 200 to $<300$ & $0.77(0.61-0.97)$ & .03 & $1.00(0.73-1.38)$ & .98 \\
\hline 300 to $<400$ & $0.78(0.61-1.01)$ & .06 & $1.10(0.78-1.55)$ & .57 \\
\hline 400 to $<500$ & $0.69(0.53-0.91)$ & .008 & $0.97(0.68-1.39)$ & .87 \\
\hline$\geq 500$ & $0.80(0.61-1.05)$ & .11 & $0.93(0.64-1.34)$ & .69 \\
\hline \multicolumn{5}{|l|}{ Medicare discharges/admissions $\|$} \\
\hline 2nd quartile & $1.05(0.84-1.31)$ & .69 & $0.80(0.60-1.08)$ & .14 \\
\hline 3rd quartile & $0.93(0.73-1.20)$ & .58 & $0.72(0.51-1.00)$ & .05 \\
\hline 4th quartile & $0.99(0.75-1.30)$ & .93 & $0.75(0.52-1.08)$ & .13 \\
\hline \multicolumn{5}{|l|}{ Medicaid discharges/admissions $\|$} \\
\hline 2nd quartile & $0.94(0.85-1.05)$ & .26 & $0.92(0.79-1.06)$ & .25 \\
\hline 3rd quartile & $1.05(0.95-1.17)$ & .31 & $0.95(0.82-1.10)$ & .50 \\
\hline 4th quartile & $0.97(0.86-1.09)$ & .58 & $0.83(0.71-0.98)$ & .02 \\
\hline \multicolumn{5}{|l|}{ RN FTEs/admissions $\|$} \\
\hline 2nd quartile & $0.99(0.89-1.11)$ & .92 & $1.10(0.93-1.29)$ & .27 \\
\hline 3rd quartile & $0.95(0.85-1.07)$ & .39 & $1.16(0.97-1.37)$ & .10 \\
\hline 4th quartile & $0.95(0.84-1.08)$ & .44 & $1.24(1.05-1.47)$ & .01 \\
\hline Metropolitan location & $0.94(0.80-1.10)$ & .45 & $0.87(0.71-1.07)$ & .20 \\
\hline \multicolumn{5}{|l|}{ County-level variables } \\
\hline \multicolumn{5}{|l|}{ PCPs/population } \\
\hline 2nd tertile & $1.02(0.91-1.14)$ & .74 & $1.13(0.96-1.33)$ & .13 \\
\hline 3rd tertile & $0.93(0.82-1.06)$ & .28 & $1.18(0.99-1.41)$ & .07 \\
\hline \multicolumn{5}{|l|}{ Neurologists/population } \\
\hline 2nd tertile & $1.05(0.91-1.20)$ & .50 & $0.98(0.80-1.19)$ & .81 \\
\hline 3rd tertile & $1.10(0.95-1.28)$ & .21 & $0.96(0.78-1.19)$ & .73 \\
\hline \multicolumn{5}{|l|}{ PMR physicians/population } \\
\hline 2nd tertile & $1.05(0.91-1.20)$ & .50 & $0.85(0.71-1.03)$ & .10 \\
\hline 3rd tertile & $0.98(0.85-1.14)$ & .81 & $0.90(0.74-1.10)$ & .32 \\
\hline
\end{tabular}




\begin{tabular}{|c|c|c|c|c|}
\hline \multirow[b]{3}{*}{ Characteristics } & \multicolumn{4}{|c|}{ Multivariate, Multinomial Logistic Regression Analysis $^{\dagger}$} \\
\hline & \multicolumn{2}{|c|}{ Therapist Use in Hospital and Home } & \multicolumn{2}{|c|}{ Therapist Use in Hospital and Outpatient Setting } \\
\hline & Odds Ratio (95\% CI) & $P$ & Odds Ratio $(95 \% \mathrm{CI})$ & $P$ \\
\hline \multicolumn{5}{|c|}{ Physical therapists/population } \\
\hline 2nd tertile & $1.04(0.91-1.20)$ & .54 & $1.10(0.90-1.34)$ & .35 \\
\hline 3rd tertile & $1.10(0.95-1.28)$ & .21 & $1.26(1.01-1.58)$ & .04 \\
\hline Metropolitan county & $1.05(0.91-1.20)$ & .52 & $0.93(0.77-1.14)$ & .50 \\
\hline \multicolumn{5}{|c|}{ Sociodemographic characteristics } \\
\hline \multicolumn{5}{|c|}{ Race $^{\#}$} \\
\hline Black & $1.28(1.14-1.44)$ & $<.001$ & $0.80(0.66-0.98)$ & .03 \\
\hline Hispanic & $0.97(0.77-1.23)$ & .83 & $0.92(0.61-1.39)$ & .70 \\
\hline Other & $0.98(0.83-1.17)$ & .86 & $0.87(0.64-1.18)$ & .37 \\
\hline Dual eligible & $1.12(1.02-1.22)$ & .02 & $0.53(0.46-0.61)$ & $<.001$ \\
\hline \multicolumn{5}{|c|}{ Median household income ${ }^{\|, * *}$} \\
\hline 2nd quartile & $0.87(0.76-1.01)$ & .07 & $1.01(0.81-1.26)$ & .95 \\
\hline 3rd quartile & $0.80(0.69-0.93)$ & .003 & $1.06(0.85-1.34)$ & .59 \\
\hline 4th quartile & $0.89(0.77-1.03)$ & .13 & $1.02(0.83-1.27)$ & .83 \\
\hline
\end{tabular}

Abbreviations: CI, confidence interval; FTE, full-time equivalent.

* Limited to patients who received inpatient therapy.

Reference no therapist use in inpatient or postacute setting or therapist use in only 1 of these settings, controlling for sex, age, baseline comorbidities and health care use, hospitalization characteristics, and comorbidities.

₹eference for profit.

$\S$ Reference $<100$ beds.

Reference 1st quartile.

Reference 1st tertile.

\# Reference white.

** County-level measure. 
Table 4 Hospital, county, and patient characteristics associated with early therapist care in the postacute settings $(N=9546)$

\begin{tabular}{|c|c|c|c|c|}
\hline \multirow[b]{3}{*}{ Characteristics } & \multicolumn{4}{|c|}{ Multivariate, Multinomial Logistic Regression Results* } \\
\hline & \multicolumn{2}{|c|}{ Early Therapist Use in Home } & \multicolumn{2}{|c|}{ Early Therapist Use in Outpatient Setting } \\
\hline & Odds Ratio (95\% CI) & $P$ & Odds Ratio (95\% CI) & $P$ \\
\hline \multicolumn{5}{|l|}{ Hospital-level characteristics } \\
\hline \multicolumn{5}{|l|}{ Ownership ${ }^{\dagger}$} \\
\hline Government & $1.30(1.06-1.61)$ & .01 & $1.60(1.18-2.18)$ & .003 \\
\hline Other not-for-profit & $1.06(0.91-1.25)$ & .45 & $1.49(1.15-1.92)$ & .003 \\
\hline Joint Commission-accredited hospital & $1.21(1.00-1.46)$ & .05 & $0.76(0.59-0.98)$ & .04 \\
\hline Medical school affiliation & $0.86(0.75-0.98)$ & .02 & $0.97(0.81-1.17)$ & .77 \\
\hline \multicolumn{5}{|l|}{ No. of beds } \\
\hline 100 to $<200$ & $0.77(0.60-0.98)$ & .04 & $1.07(0.73-1.59)$ & .72 \\
\hline 200 to $<300$ & $0.69(0.51-0.92)$ & .01 & $1.13(0.71-1.79)$ & .60 \\
\hline 300 to $<400$ & $0.77(0.56-1.06)$ & .11 & $1.29(0.78-2.12)$ & .32 \\
\hline 400 to $<500$ & $0.75(0.54-1.06)$ & .10 & $1.26(0.74-2.15)$ & .39 \\
\hline$\geq 500$ & $0.74(0.52-1.05)$ & .09 & $0.98(0.57-1.67)$ & .93 \\
\hline \multicolumn{5}{|l|}{ Medicare discharges/admissions ${ }^{\S}$} \\
\hline 2nd quartile & $0.95(0.72-1.24)$ & .71 & $0.71(0.47-1.06)$ & .09 \\
\hline 3rd quartile & $1.15(0.84-1.56)$ & .39 & $0.78(0.49-1.24)$ & .29 \\
\hline 4th quartile & $1.15(0.82-1.63)$ & .42 & $0.74(0.44-1.23)$ & .25 \\
\hline \multicolumn{5}{|l|}{ Medicaid discharges/admission ${ }^{\S}$} \\
\hline 2nd quartile & $1.17(1.02-1.35)$ & .03 & $1.13(0.93-1.39)$ & .23 \\
\hline 3rd quartile & $1.23(1.06-1.42)$ & .01 & $1.08(0.88-1.32)$ & .48 \\
\hline 4th quartile & $1.04(0.89-1.21)$ & .66 & $0.80(0.64-1.01)$ & .06 \\
\hline \multicolumn{5}{|l|}{ RN FTEs/admissions ${ }^{\S}$} \\
\hline 2nd quartile & $0.92(0.80-1.07)$ & .30 & $1.02(0.81-1.28)$ & .85 \\
\hline 3rd quartile & $0.96(0.82-1.12)$ & .63 & $1.27(1.00-1.60)$ & .05 \\
\hline 4th quartile & $1.04(0.89-1.22)$ & .63 & $1.24(0.97-1.57)$ & .08 \\
\hline Metropolitan location & $0.99(0.81-1.22)$ & .94 & $0.93(0.70-1.23)$ & .61 \\
\hline \multicolumn{5}{|l|}{ County-level variables } \\
\hline \multicolumn{5}{|l|}{ PCPs/population $\|$} \\
\hline 2nd tertile & $1.28(1.09-1.51)$ & .003 & $1.16(0.93-1.45)$ & .20 \\
\hline 3rd tertile & $1.21(1.01-1.45)$ & .04 & $1.34(1.04-1.73)$ & .02 \\
\hline \multicolumn{5}{|l|}{ Neurologists/population $\|$} \\
\hline 2nd tertile & $0.90(0.75-1.09)$ & .28 & $0.78(0.60-1.01)$ & .06 \\
\hline 3rd tertile & $1.00(0.81-1.22)$ & .97 & $0.85(0.64-1.14)$ & .28 \\
\hline \multicolumn{5}{|l|}{ PMR physicians/population $\|$} \\
\hline 2nd tertile & $0.97(0.81-1.15)$ & .70 & $0.74(0.57-0.96)$ & .03 \\
\hline 3rd tertile & $0.75(0.62-0.91)$ & .004 & $0.66(0.50-0.88)$ & .005 \\
\hline
\end{tabular}


Multivariate, Multinomial Logistic Regression Results*

\begin{tabular}{|c|c|c|c|c|}
\hline \multirow[b]{3}{*}{ Characteristics } & \multicolumn{4}{|c|}{ Multivariate, Multinomial Logistic Regression Results* } \\
\hline & \multicolumn{2}{|c|}{ Early Therapist Use in Home } & \multicolumn{2}{|c|}{ Early Therapist Use in Outpatient Setting } \\
\hline & Odds Ratio (95\% CI) & $P$ & Odds Ratio $(95 \% \mathrm{CI})$ & $P$ \\
\hline \multicolumn{5}{|c|}{ Physical therapists/population $\|$} \\
\hline 2nd tertile & $1.17(0.97-1.42)$ & .11 & $1.23(0.95-1.60)$ & .12 \\
\hline 3rd tertile & $1.31(1.06-1.61)$ & .01 & $1.34(0.99-1.81)$ & .05 \\
\hline Metropolitan county & $1.05(0.87-1.27)$ & .59 & $0.98(0.76-1.28)$ & .90 \\
\hline \multirow{2}{*}{\multicolumn{5}{|c|}{$\begin{array}{l}\text { Patient-level sociodemographic characteristics } \\
\text { Race }\end{array}$}} \\
\hline & & & & \\
\hline Black & $0.79(0.68-0.91)$ & .001 & $0.51(0.38-0.67)$ & $<.001$ \\
\hline Hispanic & $0.61(0.46-0.80)$ & $<.001$ & $0.68(0.38-1.24)$ & .21 \\
\hline Other & $1.01(0.80-1.27)$ & .95 & $0.80(0.52-1.24)$ & .32 \\
\hline Dual eligible & $1.00(0.90-1.13)$ & .93 & $0.50(0.41-0.61)$ & $<.001$ \\
\hline \multicolumn{5}{|c|}{ Median household income ${ }^{\S, \#}$} \\
\hline 2nd quartile & $1.04(0.86-1.26)$ & .67 & $1.06(0.80-1.42)$ & .67 \\
\hline 3rd quartile & $1.00(0.82-1.21)$ & .97 & $1.24(0.92-1.67)$ & .16 \\
\hline 4th quartile & $0.90(0.73-1.10)$ & .30 & $1.01(0.74-1.37)$ & .95 \\
\hline
\end{tabular}

Abbreviations: CI, confidence interval; FTE, full-time equivalent.

* Reference: later therapist use in the home or outpatient setting; controlling for age, baseline comorbidities and health care use, hospitalization characteristics and comorbidities.

$\dagger$ Reference for profit.

Reference $<100$ beds.

Reference 1st quartile.

$\|$ Reference 1st tertile.

ब Reference white.

\# County-level measure. 
severity of strokes. ${ }^{35,36}$ Unlike care in the home, which is fully covered under Medicare Part A, outpatient therapist care in the traditional Medicare program is covered under Medicare Part B and requires a $20 \%$ copayment that patients may have to pay if they do not have supplemental insurance coverage. While approximately $30 \%$ of the sample received therapist care in the home, only about $10 \%$ used outpatient therapy in the first 30 days. These findings are particularly suggestive of underuse of outpatient therapists after stroke for patients who are not homebound. Payment policy that minimizes out-of-pocket costs for outpatient therapy may help increase access to the underserved and may be an effective way to control downstream health care costs poststroke.

As the population ages and advances in medicine continue to improve the acute care of stroke, the prevalence of strokes survivors is likely to increase. Better efforts and policies are needed to promote access to and continuity in the use of therapists in the acute to postacute transition after stroke, particularly for patients discharged home. One area to target is educating nurses, physicians, and other providers in the acute and postacute settings about the roles of therapists and the importance of early and continued care after discharge home. Seamless communication and information exchange among providers in the acute and postacute settings is also important for effective care coordination and continuity of care. This could potentially be facilitated by the use of electronic health records. Our results underscore the importance of team-based models of care including PCPs, physician specialists, nurses, and therapists. As hospitals move toward accountable care organizations and bundled payments that include both acute and postacute care, strengthening continuity of therapist care across settings may be particularly useful in preventing hospital readmission and other downstream health care costs (eg, costs secondary to a fall).

\section{Study limitations}

This study has several limitations. Our findings are limited to Medicare beneficiaries and may not be generalizable to the larger population of stroke survivors. The precision or usefulness of our study variables was also limited. For example, we did not have direct measures of "need" for therapy based on therapist/physician assessment, but rather relied on proxy measures available in our data. In addition, nurse staffing and PCP supply are measures of "structure" or the attributes of settings where health care occurs ${ }^{37}$ and do not capture the processes of care (eg, appropriate discharge planning) that facilitate transitions from the acute care to the community setting. We also lacked comprehensive measures of provider supply (eg, occupational therapist supply) and granular measures of geography that may have had some impact on our findings (eg, socioeconomic disparities). Finally, we did not have any measures of patient preference or choice. Future research should explore the reasons underlying the associations we observed and attempt to determine causality.

\section{Conclusions}

Therapist use after stroke varies, particularly in the community and especially for specific racial and socioeconomic subgroups, and may be indicative of underutilization. Inpatient nurse staffing levels and primary care provider supply were the most consistent predictors of therapist use, continuity of therapist care, and early therapist use in the community after stroke.

\section{Supplier}

a. Stata version 14; StataCorp LLC.

\section{Keywords}

Continuity of patient care; Healthcare; Occupational therapists; Physical therapists; Rehabilitation; Stroke

\section{Corresponding author}

Janet K. Freburger, PT, PhD, Department of Physical Therapy, University of Pittsburgh, Bridgeside Point 1, 100 Technology Dr, Ste 210, Pittsburgh, PA. E-mail address: janet_freburger@pitt. edu.

\section{References}

1. Lawrence ES, Coshall C, Dundas R, et al. Estimates of the prevalence of acute stroke impairments and disability in a multiethnic population. Stroke 2001;32:1279-84.

2. Pollock A, Baer G, Campbell P, et al. Physical rehabilitation approaches for the recovery of function and mobility following stroke. Cochrane Database Syst Rev 2014;4:CD001920.

3. Gresham GE, Fitzpatrick TE, Wolf PA, et al. Residual disability in survivors of stroke - the Framingham study. N Engl J Med 1975;293:954-6.

4. Kind AJ, Smith MA, Liou JI, et al. The price of bouncing back: oneyear mortality and payments for acute stroke patients with 30-day bounce-backs. J Am Geriatr Soc 2008;56:999-1005.

5. Mackintosh SF, Hill KD, Dodd KJ, et al. Balance score and a history of falls in hospital predict recurrent falls in the 6 months following stroke rehabilitation. Arch Phys Med Rehabil 2006;87:1583-9.

6. Simpson LA, Miller WC, Eng JJ. Effect of stroke on fall rate, location and predictors: a prospective comparison of older adults with and without stroke. PLoS One 2011;6:e19431.

7. Verheyden GS, Weerdesteyn V, Pickering RM, et al. Interventions for preventing falls in people after stroke. Cochrane Database Syst Rev 2013;5:CD008728.

8. Billinger SA, Arena R, Bernhardt J, et al. Physical activity and exercise recommendations for stroke survivors: a statement for healthcare professionals from the American Heart Association/American Stroke Association. Stroke 2014;45:2532-53.

9. Lang CE, Lohse KR, Birkenmeier RL. Dose and timing in neurorehabilitation: prescribing motor therapy after stroke. Curr Opin Neurol 2015;28:549-55.

10. Horn SD, DeJong G, Smout RJ, et al. Stroke rehabilitation patients, practice, and outcomes: is earlier and more aggressive therapy better? Arch Phys Med Rehabil 2005;86(12 Suppl 2):S101-14.

11. Quinn TJ, Paolucci S, Sunnerhagen KS, et al. Evidence-based stroke rehabilitation: an expanded guidance document from the European Stroke Organisation (ESO) guidelines for management of ischaemic stroke and transient ischaemic attack 2008. J Rehabil Med 2009;41:99-111.

12. Van Peppen RP, Kwakkel G, Wood-Dauphinee S, et al. The impact of physical therapy on functional outcomes after stroke: what's the evidence? Clin Rehabil 2004;18:833-62.

13. Andrews AW, Li D, Freburger JK. Association of rehabilitation intensity for stroke and risk of hospital readmission. Phys Ther 2015;95: 1660-7.

14. Burke JF, Skolarus LE, Adelman EE, et al. Influence of hospital-level practices on readmission after ischemic stroke. Neurology 2014;82: 2196-204. 
15. Eng JJ, Pang MY, Ashe MC. Balance, falls, and bone health: role of exercise in reducing fracture risk after stroke. J Rehabil Res Dev 2008; 45:297-313.

16. European Stroke Organisation (ESO) Executive Committee; ESO Writing Committee. Guidelines for management of ischaemic stroke and transient ischaemic attack 2008. Cerebrovasc Dis 2008;25:457-507.

17. Dworzynski K, Ritchie G, Fenu E, et al. Rehabilitation after stroke: summary of NICE guidance. BMJ 2013;346:f3615.

18. Lindsay P, Bayley M, McDonald A, et al. Toward a more effective approach to stroke: Canadian Best Practice Recommendations for Stroke Care. CMAJ 2008;178:1418-25.

19. Prvu Bettger J, McCoy L, Smith EE, Fonarow GC, Schwamm LH, Peterson ED. Contemporary trends and predictors of postacute service use and routine discharge home after stroke. J Am Heart Assoc 2015; 4:e001038.

20. Freburger JK, Holmes GM, Ku LJ, et al. Disparities in postacute rehabilitation care for stroke: an analysis of the state inpatient databases. Arch Phys Med Rehabil 2011;92:1220-9.

21. Ayanian JZ, Weissman JS. Teaching hospitals and quality of care: a review of the literature. Milbank Q 2002;80:569-93.

22. Goldman LE, Vittinghoff E, Dudley RA. Quality of care in hospitals with a high percent of Medicaid patients. Med Care 2007;45:579-83.

23. Kane RL, Shamliyan T, Mueller C, et al. Nurse staffing and quality of patient care. Evid Rep Technol Assess (Full Rep) 2007;(151):1-115.

24. Kane RL, Shamliyan TA, Mueller C, et al. The association of registered nurse staffing levels and patient outcomes: systematic review and meta-analysis. Med Care 2007;45:1195-204.

25. Carretta HJ, Chukmaitov A, Tang A, et al. Examination of hospital characteristics and patient quality outcomes using four inpatient quality indicators and 30-day all-cause mortality. Am J Med Qual 2013;28:46-55.

26. Saposnik G, Jeerakathil T, Selchen D, et al. Socioeconomic status, hospital volume, and stroke fatality in Canada. Stroke 2008;39:3360-6.
27. Tirschwell DL, Longstreth WT Jr. Validating administrative data in stroke research. Stroke 2002;33:2465-70.

28. Thigpen JL, Dillon C, Forster KB, et al. Validity of international classification of disease codes to identify ischemic stroke and intracranial hemorrhage among individuals with associated diagnosis of atrial fibrillation. Circ Cardiovasc Qual Outcomes 2015;8:8-14.

29. Spolaore P, Brocco S, Fedeli U, et al. Measuring accuracy of discharge diagnoses for a region-wide surveillance of hospitalized strokes. Stroke 2005;36:1031-4.

30. Roumie CL, Mitchel E, Gideon PS, et al. Validation of ICD-9 codes with a high positive predictive value for incident strokes resulting in hospitalization using Medicaid health data. Pharmacoepidemiol Drug Saf 2008;17:20-6.

31. Jones SA, Gottesman RF, Shahar E, et al. Validity of hospital discharge diagnosis codes for stroke: the Atherosclerosis Risk in Communities Study. Stroke 2014;45:3219-25.

32. Amico P, Pope P, Pardasaney P, et al. Developing outpatient therapy payment alternatives: payment alternatives report. RTI Project No. 0213520.000.004. Research Triangle Park, NC: RTI International; 2014.

33. Faurot KR, Jonsson Funk M, Pate V, et al. Using claims data to predict dependency in activities of daily living as a proxy for frailty. Pharmacoepidemiol Drug Saf 2015;24:59-66.

34. Sasichay-Akkadechanunt T, Scalzi CC, Jawad AF. The relationship between nurse staffing and patient outcomes. J Nurs Adm 2003;33: 478-85.

35. Howard VJ. Reasons underlying racial differences in stroke incidence and mortality. Stroke 2013;44(6 Suppl 1):S126-8.

36. Stansbury JP, Jia H, Williams LS, Vogel WB, Duncan PW. Ethnic disparities in stroke: epidemiology, acute care, and postacute outcomes. Stroke 2005;36:374-86.

37. Donabedian A. The quality of care. How can it be assessed? JAMA 1988;260:1743-8 
Supplemental Table S1 ICD-9-CM diagnosis codes to identify stroke

\begin{tabular}{lll}
\hline ICD Code & Description & Type of Stroke \\
\hline 430 & Subarachnoid hemorrhage & Hemorrhagic \\
431 & Intracerebral hemorrhage & Hemorrhagic \\
432 & Other unspecified hemorrhage & Hemorrhagic \\
433.01 & Basilar artery; with cerebral infarction & Ischemic \\
433.11 & Carotid artery; with cerebral infarction & Ischemic \\
433.21 & Vertebral artery; with cerebral infarction & Ischemic \\
433.31 & Multiple and bilateral; with cerebral infarction & Ischemic \\
433.81 & Other specified precerebral artery; with cerebral infarction & Ischemic \\
433.91 & Unspecified precerebral artery; with cerebral infarction & Ischemic \\
434.01 & Cerebral thrombosis; with cerebral infarction & Ischemic \\
434.11 & Cerebral embolism; with cerebral infarction & Ischemic \\
434.91 & Cerebral artery occlusion, unspecified; with cerebral infarction & Ischemic \\
435 & Transient cerebral ischemia & Transient ischemic attack \\
435.0 & Basilar artery syndrome & Transient ischemic attack \\
435.1 & Vertebral artery syndrome & Transient ischemic attack \\
435.2 & Subclavian steal syndrome & Transient ischemic attack \\
435.3 & Vertebrobasilar artery syndrome & Transient ischemic attack \\
435.8 & Other specified transient cerebral ischemias & Transient ischemic attack \\
435.9 & Unspecified transient cerebral ischemia & Transient ischemic attack \\
436 & Acute, but ill-defined, cerebrovascular disease & Ischemic \\
437.1 & Other generalized ischemic cerebrovascular disease & Ischemic \\
\hline
\end{tabular}

Abbreviation: ICD-9-CM, International Classification of Diseases, Ninth Revision, Clinical Modification. 
Variable

Sex

Age

Race

Dual eligibility

Median household income of patient's

county of residence

Hospitalization characteristics

Patient admitted through emergency

department

Patient transferred from another hospital

Type of stroke

Stroke code in principal discharge diagnosis

Length of stay

Use of intensive care

Use of coronary care

Physical therapist use

Occupational therapist use

Speech therapist use

Stroke-related comorbidities

Altered consciousness

Aphasia

Dysphagia

Aspiration pneumonia

Decubitus

Dementia

Movement abnormalities

Hemiparesis

Falls

Incontinence

Malnutrition

Atrial fibrillation

Hypertensive heart disease

Ischemic heart disease

Vascular procedures
Definition

Data Source

Male $=1$, Female $=0$

Age at hospital admission, categorized: $66-70,71-75,76-80,81-85,86-90,>90$ years

Categorized as white, black, Hispanic, other

Medicare and Medicaid, coded as $1=$ yes, $0=$ no

Categorical variables based on quartile distribution of median household income at the county level

$1=$ yes, $0=$ no based on type of admission variable

$1=$ yes, $0=$ no based on source of admission variable

Ischemic, hemorrhagic, or transient ischemic attack. Coded 0 or 1 based on ICD-9-CM codes (see supplemental table S1)

Coded as 1 if principal discharge diagnosis is for stroke, 0 if stroke diagnosis in a secondary position

Categorized as $1,2,3-4,5-7,8-10,>10$ days

Based on revenue codes for ICU use, coded 1 if yes, 0 if no

Based on revenue codes for ICU use, coded 1 if yes, 0 if no

Based on revenue codes for use, coded as 1 if yes, 0 if no (see supplemental table S3)

Based on revenue codes for use, coded as 1 if yes, 0 if no (see supplemental table S3)

Based on revenue codes for use, coded as 1 if yes, 0 if no

ICD-9-CM diagnosis codes 780, 780.0, 780.02, 780.03

ICD-9-CM diagnosis codes 438.1, 438.11, 784.3, 784.6

ICD-9-CM diagnosis codes 438.82, 787.2, 787.20, 787.21, 787.22, 787.23, 787.24, 787.29

ICD-9-CM diagnosis codes 507, 507.0, 507.1, 507.8

ICD-9-CM diagnosis codes 707, 707.0, 707.1, 707.10, 707.11, 707.12, 707.13, 707.14, 707.15, 707.19, 707.2, 707.20,

$707.21,707.22,707.23,707.24,707.25,707.8,707.9$

ICD-9-CM diagnosis codes 290, 290.1, 290.11, 290.3, 290.4, 290.41, 291.0, 292.81, 293.0, 293.1

ICD-9-CM diagnosis codes $781.0,781.2,781.3$

ICD-9-CM diagnosis codes 782, 342.ss, 368.46, 781.8, 438.2, 432.12, 438.22, 438.3, 438.31, 438.32, 438.4, 438.41,

$438.42,438.5,438.51,438.52,438.53,438.6,438.7,438.84$

ICD-9-CM diagnosis codes E880, E880.9, E884.2, E884.3, E884.4, E884.5, E884.6, E884.9, E885, E886.9, E888, E888.0,

E888.1, E888.8, E888.9, E9293, 719.7, 719.70, 719.75, 719.76, 719.77, 719.78, 719.79

ICD-9-CM diagnosis codes 596.5, 596.51-596.55, 596.59, 788.2, 788.20, 788.21, 788.29, 788.3, 788.30-788.39

ICD-9-CM diagnosis codes $260,262,262,263,263.1,263.2,26.8,253.9$

ICD-9-CM diagnosis codes 427.3, 427.31, 427.32

ICD-9-CM diagnosis codes 402.xx

ICD-9-CM diagnosis codes 410.xx-414.xx

ICD-9-CM diagnosis codes 38.11, 28.12, 00.61-00.65, 17.53, 17.54, 38.01, 38.02, 38.31, 38.32, 38.41, 38.42, 38.51, $38.52,38.61,38.62,38.81,38.83,39.72,39.75,39.76,39.81-39.89$
Medicare MedPAR

file

Medicare Beneficiary Summary File

Area Resource File

Medicare MedPAR

file 


\begin{tabular}{l} 
Variable \\
\hline $\begin{array}{l}\text { Other comorbidities (Elixhauser } \\
\text { comorbidities) }\end{array}$
\end{tabular}

comorbidities)

Elixhauser Comorbidity Index

Baseline frailty comorbidities and health care use

Use of screening tests

Use of wheelchair

Use of other assistive devices

Parkinson disease

Weakness

Vertigo

Falls/difficulty walking

Incontinence

Decubitus

Use of oxygen

Use of hospital bed

Use of ambulance

Nail care

Hospitalization

Skilled nursing facility admissions
Definition

Data Source

29 comorbidity variables, see the following link: https://www.hcup-us.ahrq.gov/toolssoftware/comorbidity/comorbidity. jsp

Created a dichotomous variable for each comorbidity identified during hospitalization and/or during baseline and a categorical count variable $(<2,2-4,5-7,8-10,>10$ comorbidities)

HCPCS/CPT codes: G0009, 90669, 90732, 80061, 82465, 83715, 83716, 83717, 83718, 83719, 83720, 83721, 84478, 83700, 83701, 83704, G0101, G0202, 3014F, 76083, 77052, 76092, 77057, 3017F, G0104, G0105, G0106, G0107, G0120, G0121, G0122, G0328, G0102, G0103, 84153, 84154

ICD-9-CM diagnosis codes: V7644, V771, V7791, V761, V7610, V7611, V7612, V7651

CPT/HCPCS codes: 97542, E0950-E0986, E0988, E0990-E1039, E1050, E1060, E1065, E1066, E1069, E1070,

E1083-E1093, E1100,E1110,E1130, E1140, E1150, E1160, E1161,E1170-E1172,E1180, E1190, E1195, E1210-E1213, E1220-E1228，E1240，E1250，E1260，E1270，E1280, E1285, E1290，E1295-E1298，E2201-E2228，E2230，E2231，E2300， E2301, E2310-E2313, E2320-E2331, E2340-E2343, E2351, Е2358-E2377, E2381-E2397, E2399, Е2601-E2633, G9156, K0001-K0109, K0114-K0116, K0195, K0452, K0460, K0461, K0650-K0669, K0733-K0737, K0813-K0816, K0820-K0831, K0835-K0843, K0848-K0864, K0868-K0886, K0890, K0891, K0898, L3964, L3965, L3966 ICD-9-CM diagnosis codes: V463, V538

HCPCS: A4635-A4637, E0100, E0105, E0110-E0114, E0116-E0118, E0130, E0135, E0140-E0149, E0153-E0159, E0163-E0172, E0175, E0240-E0248, K0457-K0459, L0978

ICD-9-CM diagnosis codes: $332,3320,3321$

ICD-9-CM diagnosis codes: 7282, 7283, 7287, 7993, V4984

ICD-9-CM diagnosis codes: 386, 3860, 38600, 38601, 38602, 38603, 38604, 3861, 38610, 38611, 38612, 38619, 3862 43885,7804

ICD-9-CM diagnosis codes: 7197, 71970, 71975, 71976, 71977, 71978, 71979, 7812, V1588, E880, E8800, E8801, E8809, E8842, E8843, E8844, E8845, E8846, E8859, E888, E8880, E8881, E8888, E8889, E9293

ICD-9-CM diagnosis codes: 5965, 59651, 59652, 59653, 59654, 59655, 59659, 7882, 78820, 78821, 78829, 7883, 78830, $78831,78832,78833,78834,78835,78836,78837,78838,78839$

ICD-9-CM diagnosis codes: 7070, 7071, 70710, 70711, 70712, 70713, 70714, 70715, 70719, 7072, 70720, 70721, 70722 , 70723, 70724, 70725, 7078, 7079

HCPCS codes: E0431, E0433, E0434, E0435, E0439, E0441, E0442, E0443, E1390, E1393, K0671

HCPCS codes: E0250, E0251, E0255, E0256, E0260, E0261, E0265, E0266, E0270, E0290, E0291, E0292, E0293, E0294,

E0295, E0296, E0297, E0301, E0302, E0303, E0304, E0316, K0456, K0459, K0550

HCPCS codes: A0426, A0427, A0428, A0429, A0999

HCPCS and CPT codes: 11700, 11701, 11710, 11711, 11719, 11720, 11721, G0127, G0247, M0101

Number of hospitalizations during baseline period categorized as $0,1,2$ or more.

SNF admission during baseline period (Yes or No)
Medicare MedPAR file, outpatient file, home health file, carrier file

Medicare MedPAR file, outpatient file, home health file, carrier file, and durable medical equipment file
From MedPAR files From MedPAR files

(continued on next page) 


\begin{tabular}{|c|c|c|}
\hline Variable & Definition & Data Source \\
\hline Use of PTs or OTs during baseline & $\begin{array}{l}\text { Indicator for outpatient therapy use, home health therapy use, use in short-stay hospital, use in SNF or long-term care } \\
\text { hospital (see supplemental tables S3 and S4 for therapy codes) }\end{array}$ & $\begin{array}{l}\text { From MedPAR, } \\
\text { outpatient, } \\
\text { carrier, home } \\
\text { health files }\end{array}$ \\
\hline $\begin{array}{l}\text { Use of speech therapists during } \\
\text { baseline }\end{array}$ & Indicator for speech therapist use during baseline in an inpatient setting based on revenue center codes & From MedPAR files \\
\hline \multicolumn{3}{|l|}{$\begin{array}{l}\text { Hospital structural and organizational } \\
\text { characteristics }\end{array}$} \\
\hline Hospital ownership & Coded as for-profit, not-for-profit government, or not-for-profit other & \multirow{8}{*}{$\begin{array}{l}\text { American Hospital } \\
\text { Association data } \\
\text { file or CMS } \\
\text { Provider of Service } \\
\text { File }\end{array}$} \\
\hline Medical school affiliation & Coded as yes, no & \\
\hline RN FTEs/admissions & RN FTEs/number of hospital admissions, created categorical variables based on quartile distribution at hospital level & \\
\hline Proportion of Medicare discharges & Medicare discharges/admissions, created categorical variables based on quartile distribution at hospital level & \\
\hline Proportion of Medicaid discharges & Medicaid discharges/admissions, created categorical variables based on quartile distribution at hospital level & \\
\hline JCAHO accreditation & Coded as yes, no & \\
\hline Bed size & Categorized as $<100,100$ to $<200,200$ to $<300,300$ to $<400,400$ to $<500, \geq 500$ & \\
\hline Metropolitan location & Yes if in a micropolitan or metropolitan area, no otherwise & \\
\hline \multicolumn{3}{|l|}{ County-level variables } \\
\hline Metropolitan county & Micropolitan or metropolitan area, $1=$ yes and $0=$ no & \multirow{5}{*}{$\begin{array}{l}\text { Area Health } \\
\text { Resource File }\end{array}$} \\
\hline PTs/county population $(10,000)$ & 3-level categorical variable based on tertile distribution of PTs at county level & \\
\hline $\begin{array}{l}\text { Primary care providers/county } \\
\text { population }(10,000)\end{array}$ & 3-level categorical variable based on the tertile distribution of PCP providers at county level & \\
\hline $\begin{array}{l}\text { PMR physicians/county population } \\
(10,000)\end{array}$ & 3-level categorical variable based on tertile distribution of PMR physicians at the county level & \\
\hline Neurologists/county population & 3-level categorical variable & \\
\hline \multicolumn{3}{|l|}{ Outcome variables } \\
\hline Inpatient therapist use & $\begin{array}{l}\text { Dichotomous variable: patient received care from based on tertile distribution of neurologists in the county a therapist } \\
\text { during his/her index admission for stroke }\end{array}$ & \multirow{4}{*}{$\begin{array}{l}\text { MedPar, outpatient, } \\
\text { home health, and } \\
\text { carrier files (see } \\
\text { supplemental } \\
\text { tables S3 and S4 } \\
\text { for specific } \\
\text { therapy codes) }\end{array}$} \\
\hline Postacute therapist use & $\begin{array}{l}\text { Categorical variable: patient received care from a therapist in his/her home in the first } 30 \text { days after discharge, patient } \\
\text { received care from a therapist in an outpatient setting in the first } 30 \text { days, patient did not receive care from a therapist } \\
\text { in the first } 30 \text { days. Patients who received care in the home and outpatient setting were categorized based on first } \\
\text { setting where care was received. }\end{array}$ & \\
\hline Inpatient and postacute therapist use & $\begin{array}{l}\text { Categorical variable: patient received care from a therapist during his/her inpatient stay and in the home, patient received } \\
\text { care from a therapist during his/her inpatient stay and in an outpatient setting, patient received inpatient care only or } \\
\text { postacute care only }\end{array}$ & \\
\hline Early postacute care therapist use & $\begin{array}{l}\text { Categorical variable: patient received home health within first } 3 \text { days after discharge home, patient received outpatient } \\
\text { care within the first } 6 \text { days after discharge home, patient received therapist care later }\end{array}$ & \\
\hline
\end{tabular}

Abbreviations: CMS, Centers for Medicare and Medicaid Services; CPT, Current Procedural Terminology; FTE, full-time equivalent; HCPCS, Healthcare Common Procedure Coding System; ICD-9-CM, International Classification of Diseases, Ninth Revision, Clinical Modification; ICU, intensive care unit; JCAHO, Joint Commission of Accreditation of Healthcare Organizations; OT, occupational therapist; PT, physical therapist; SNF, skilled nursing facility. 
Supplemental Table S3 Revenue center codes for therapy

Revenue Center Codes

$0420=$ Physical therapy-general classification

$0421=$ Physical therapy-visit charge

0422 = Physical therapy-hourly charge

$0423=$ Physical therapy - group rate

0424 = Physical therapy-evaluation or re-evaluation

$0429=$ Physical therapy-other

$0430=0$ ccupational therapy-general classification

$0431=0$ occupational therapy-visit charge

0432 = 0ccupational therapy-hourly charge

$0433=0$ 0ccupational therapy-group rate

$0434=0$ 0ccupational therapy-evaluation or re-evaluation

$0439=0$ ccupational therapy-other (may include restorative therapy)

$0977=$ Professional fees - physical therapy

$0978=$ Professional fees-occupational therapy 
Supplemental Table S4 Therapy CPT/HCPCS codes*

\begin{tabular}{|c|c|c|c|c|c|}
\hline Codetype & Code & Description & Codetype & Code & Description \\
\hline Proc CPT & 64550 & Apply neurostimulator & Proc CPT & 97032 & Electrical stimulation \\
\hline Proc CPT & 90901 & Biofeedback train, any meth & Proc CPT & 97033 & Electric current therapy \\
\hline Proc CPT & 90911 & Biofeedback peri/uro/rectal & Proc CPT & 97034 & Contrast bath therapy \\
\hline Proc CPT & 92506 & Speech/hearing evaluation & Proc CPT & 97035 & Ultrasound therapy \\
\hline Proc CPT & 92507 & Speech/hearing therapy & Proc CPT & 97036 & Hydrotherapy \\
\hline Proc CPT & 92508 & Speech/hearing therapy & Proc CPT & 97039 & Physical therapy treatment \\
\hline Proc CPT & 92520 & Laryngeal function studies & Proc CPT & 97110 & Therapeutic exercises \\
\hline Proc CPT & 92526 & Oral function therapy & Proc CPT & 97112 & Neuromuscular reeducation \\
\hline Proc CPT & 92597 & Oral speech device eval & Proc CPT & 97113 & Aquatic therapy/exercises \\
\hline Proc CPT & 92605 & Ex for nonspeech device $r x$ & Proc CPT & 97116 & Gait training therapy \\
\hline Proc CPT & 92606 & Nonspeech device service & Proc CPT & 97124 & Massage therapy \\
\hline Proc CPT & 92607 & Ex for speech device $r x, 1 h$ & Proc CPT & 97139 & Physical medicine procedure \\
\hline Proc CPT & 92608 & Ex for speech device $r x$ addl & Proc CPT & 97140 & Manual therapy \\
\hline Proc CPT & 92609 & Use of speech device service & Proc CPT & 97150 & Group therapeutic procedures \\
\hline Proc CPT & 92610 & Evaluate swallowing function & Proc CPT & 97530 & Therapeutic activities \\
\hline Proc CPT & 92611 & Motion fluoroscopy/swallow & Proc CPT & 97532 & Cognitive skills development \\
\hline Proc CPT & 92612 & Endoscopy swallow tst (fees) & Proc CPT & 97533 & Sensory integration \\
\hline Proc CPT & 92614 & Laryngoscopic sensory test & Proc CPT & 97535 & Self-care management training \\
\hline Proc CPT & 92616 & Fees w/laryngeal sense test & Proc CPT & 97537 & Community/work reintegration \\
\hline Proc CPT & 92618 & Ex for nonspeech dev rx add & Proc CPT & 97542 & Wheelchair management training \\
\hline Proc CPT & 95831 & Limb muscle testing, manual & Proc CPT & 97597 & Rmvl devital tis $20 \mathrm{~cm} /<$ \\
\hline Proc CPT & 95832 & Hand muscle testing, manual & Proc CPT & 97598 & Rmvl devital tis addl $20 \mathrm{~cm}<$ \\
\hline Proc CPT & 95833 & Body muscle testing, manual & Proc CPT & 97602 & Wound(s) care nonselective \\
\hline Proc CPT & 95834 & Body muscle testing, manual & Proc CPT & 97605 & Neg press wound $t x,<50 \mathrm{~cm}$ \\
\hline Proc CPT & 95851 & Range-of-motion measurements & Proc CPT & 97606 & Neg press wound $t x,>50 \mathrm{~cm}$ \\
\hline Proc CPT & 95852 & Range-of-motion measurements & Proc CPT & 97750 & Physical performance test \\
\hline Proc CPT & 95992 & Canalith repositioning proc & Proc CPT & 97755 & Assistive technology assessment \\
\hline Proc CPT & 96105 & Assessment of aphasia & Proc CPT & 97760 & Orthotic mgmt and training \\
\hline Proc CPT & 96110 & Developmental test, lim & Proc CPT & 97761 & Prosthetic training \\
\hline Proc CPT & 96111 & Developmental test, extend & Proc CPT & 97762 & c/0 for orthotic/prosth use \\
\hline Proc CPT & 96125 & Cognitive test by $\mathrm{HC}$ pro & Proc CPT & 97799 & Physical medicine procedure \\
\hline Proc CPT & 97001 & PT evaluation & Proc CPT & 0019T & Extracorp shock wv tx ms NOS \\
\hline Proc CPT & 97002 & PT re-evaluation & Proc CPT & 0183T & Wound ultrasound \\
\hline Proc CPT & 97003 & OT evaluation & Proc HCPCS & G0281 & Elec stim unattend for press \\
\hline Proc CPT & 97004 & OT re-evaluation & Proc HCPCS & G0283 & Elec stim other than wound \\
\hline Proc CPT & 97010 & Hot or cold packs therapy & Proc HCPCS & G0329 & Electromagntic tx for ulcers \\
\hline Proc CPT & 97012 & Mechanical traction therapy & & & \\
\hline Proc CPT & 97016 & Vasopneumatic device therapy & & & \\
\hline Proc CPT & 97018 & Paraffin bath therapy & & & \\
\hline Proc CPT & 97022 & Whirlpool therapy & & & \\
\hline Proc CPT & 97024 & Diathermy, eg, microwave & & & \\
\hline Proc CPT & 97026 & Infrared therapy & & & \\
\hline Proc CPT & 97028 & Ultraviolet therapy & & & \\
\hline
\end{tabular}

Abbreviations: addl, additional; C/0, care of; CPT, Current Procedural Terminology; dev, device; devital, devitalized; Elec, electric; eval, evaluation; Electromagntic, electromagnetic; Ex, exercise; Extracorp, extracorporeal; HC, healthcare; HCPCS, Healthcare Common Procedure Coding System; lim, limited; meth, method; ms, musculoskeletal system; Neg, negative; NOS, not otherwise specified; OT, occupational therapy; press, pressure; pro, professional; Proc, procedure; prosth, prosthetic; PT, physical therapy; Rmvl, removal; rx, prescription; stim, stimulation; tis, tissue; tst, test; tx, treatment; w/, with; wv, wave.

* For this analysis, speech-related codes and wound therapy codes were excluded. 


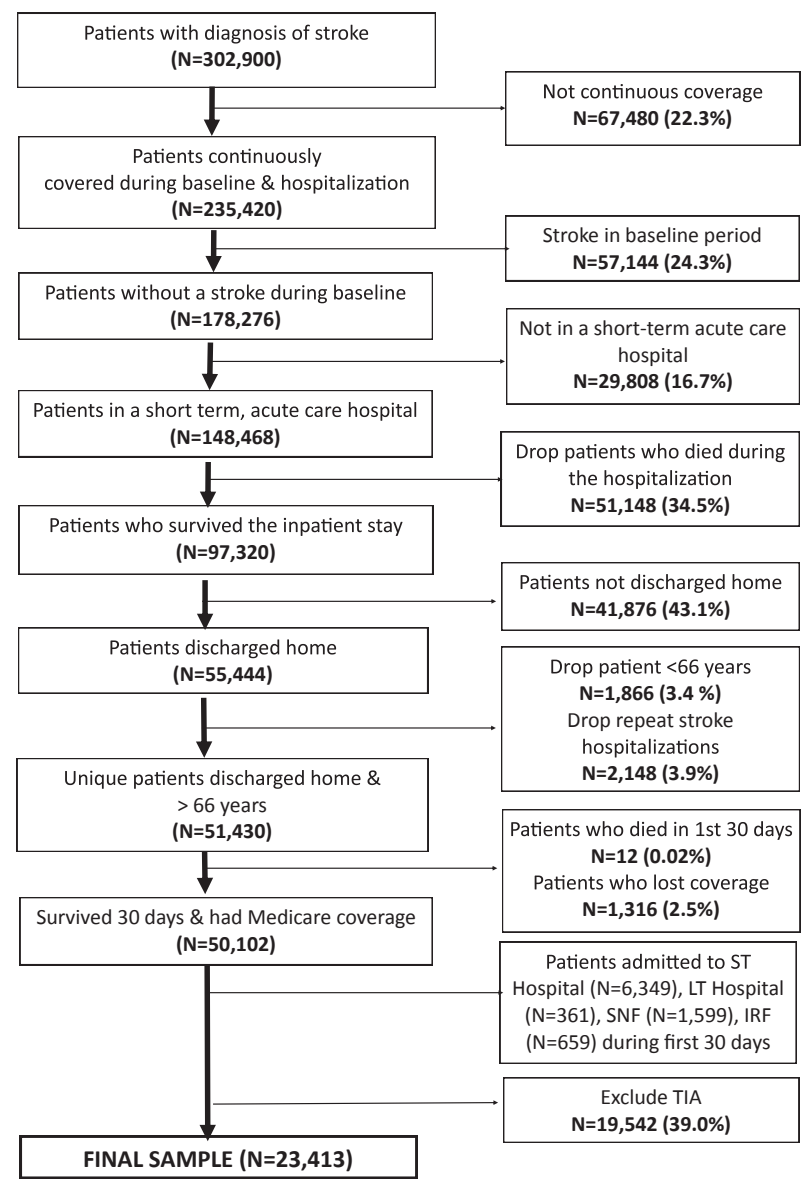

Supplemental Fig S1 Cohort creation. Abbreviations: IRF, inpatient rehabilitation facility; LT, long-term; SNF, skilled nursing facility; ST, short-term; TIA, transient ischemic attack. 